\title{
La construcción de "aprendices de lengua inglesa” (ELL) \\ Un análisis de procesos de registro y efectos de Estado en la escolarización de estudiantes migrantes multilingües*
}

James Collins**:

\author{
Traducción: Natalia Lozano \\ Revisión: Mercedes Hirsch
}

\section{Resumen}

Las migraciones de las décadas recientes han aumentado la diversidad lingüística de América, lo que alimenta controversias acerca de la educación bilingüe y revela el punto en que la identidad nacional se entremezcla con supuestos acerca del lenguaje y la raza. Partiendo de un análisis de los debates políticos acerca de la legislación federal y la política educativa conocida como Ningún Niño Dejado Atrás (No Child Left Behind, NCLB) y los estudios etnográficos de hogares de migrantes multilingües así como prácticas de escolarización del norte del Estado de Nueva York, examino cómo los metadiscursos acerca de lenguas y personas circulan a través de eventos discursivos y espacios sociales de diferentes escalas, que incluyen audiencias en el Congreso e investigaciones académicas acerca de NCLB, así como los ámbitos escolares en los que, en cada escuela, se ponen en práctica las políticas educativas destinadas a estudiantes clasificados como "aprendices de lengua inglesa". Mi análisis utiliza teorías antropológicas de registro, racialización y del Estado para investigar cómo son coconstruidas las inequidades lingüísticas y sociales en una era de creciente polarización social. Dicha coconstrucción depende de formas de gubernamentalidad, formas de efectos de Estado descentralizados, que operan a través de las fronteras aparentes entre Estado y sociedad civil, y resultan tanto de procesos "de arriba hacia abajo" como "de abajo hacia arriba"; de mandatos políticos así como de categorías locales de "buenas" y "malas" minorías. El análisis revela conexiones complejas y duraderas entre el lenguaje, la raza y la desigualdad en los procesos de educación; su crítica sigue siendo una tarea apremiante para la antropología de la educación.

*El presente artículo es una traducción de "Constructing English Language Learners: an analysis of register processes and state effects in the schooling of multilingual migrant students". Escrito revisado en profundidad de una conferencia presentada inicialmente en la 112th Annual Meeting of the American Anthropological Association, Chicago, en 2013. La presente versión revisada ha sido publicada en Tilburg University Working Papers in Cultural Studies, 96, 2014.

** University at Albany/SUNY. Correo electrónico: jcollins@albany.edu.

Palabras clave

Migrantes; Educación multilíngue; Lenguaje; Política educativa; Desigualdad 


\section{Constructing English Language Learners: an analysis of register processes and state effects in the schooling of multilingual migrant students}

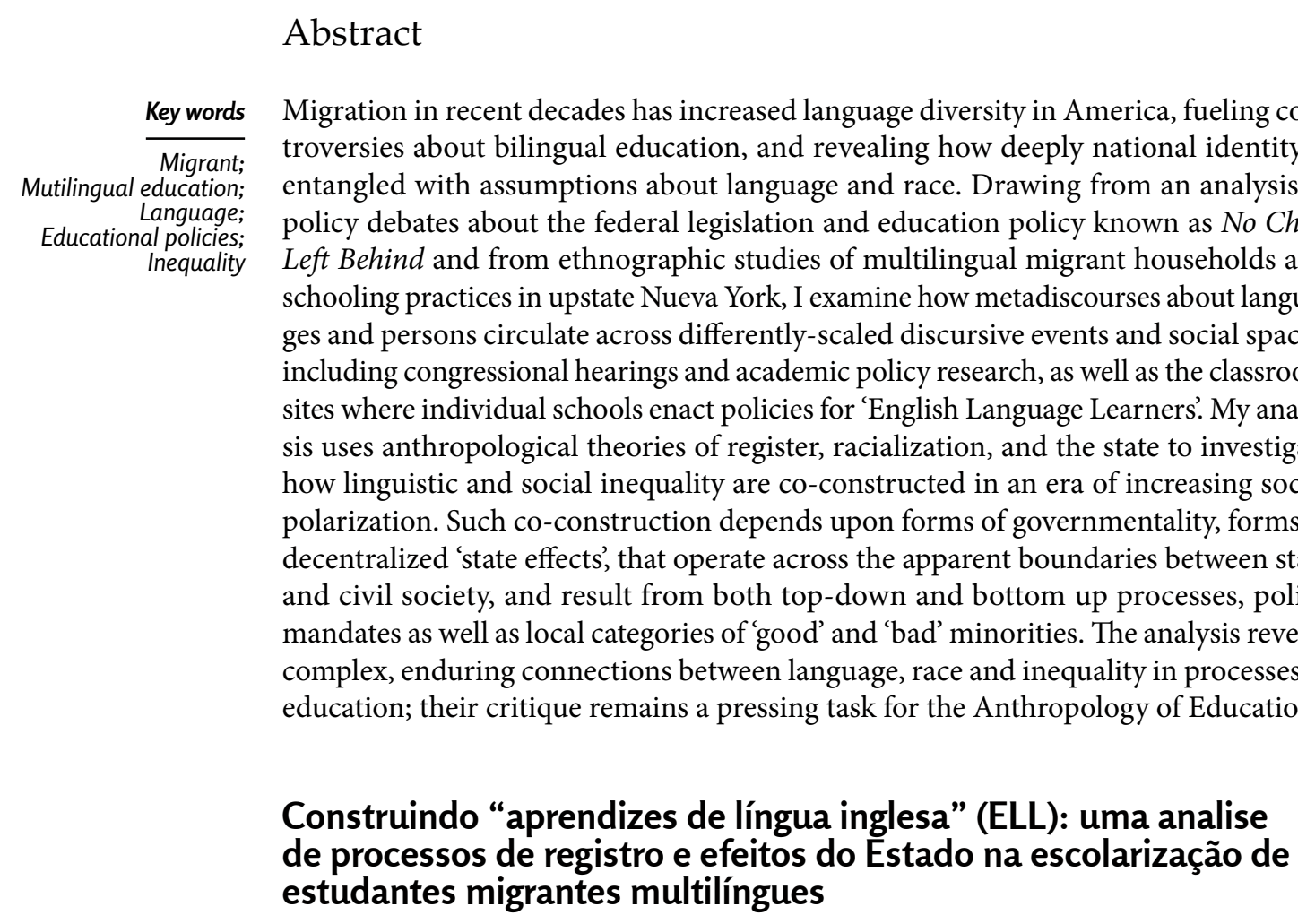

\section{Resumo}

Palavras-chave Migrações; Educação multilíngue; Linguagem; Política educativa Desigualdade
As migrações das décadas recentes aumentaram a diversidade linguística de América, alimentando controvérsias em relação à educação bilíngue, e revelando o ponto no qual a identidade nacional se mistura com supostos em relação ao linguagem e a raça. Partindo de uma análise dos debates políticos em relação a legislação federal e a política educativa conhecida como Ningún Niño Dejado Atrás (No Child Left Behind, NCLB [Nenhuma criança pra trás]) e aos estudos etnográficos de lares de migrantes multilíngues assim como às prácticas de escolarização da área norte do Estado de Nueva York, examino como os meta-discursos em relação a línguas e pessoas circulam através de eventos discursivos e espaços sociais em diferentes escalas, que incluem audiências no Congresso e investigações académicas acerca da NCLB, assim como os âmbitos escolares nos quais, en cada escola, se põem em prática as políticas educativas orientadas a estudantes classificados como "aprendizes de língua inglesa". Meu análise utiliza teorias antropológicas de registro, racialização e do estado para pesquisar como são co-construídas as inequidades linguísticas e sociais numa era de crescente polarização social. Dita co-construção depende de formas de gubernamentalidade, formas de efeitos de estado descentralizados, que operam através das fronteiras aparentes entre estado y sociedade civil, e resultam tanto de processos "de encima para abaixo" como "de abaixo para encima", de mandatos políticos assim como de categorias locais de "boas" y "más" minorias. A análise revela conexões complexas e duradouras entre a linguagem, a raça e a desigualdade nos processos de educação; sua crítica continua sendo uma tarefa urgente para a Antropología da Educação. 


\section{Introducción}

Las migraciones de las décadas recientes han aumentado la diversidad lingüística de América, lo que alimenta controversias acerca de la educación bilingüe y revela el punto en que la identidad nacional se entremezcla con supuestos acerca de lenguaje, clase y raza (Crawford, 2001; Silverstein, 2003; Huntington, 2004). Partiendo de un análisis de los debates políticos acerca de la legislación federal y la política educativa conocida como Ningún Niño Dejado Atrás (No Child Left Behind, NCLB) y estudios etnográficos de hogares de migrantes multilingües, así como de prácticas de escolarización del norte del estado de Nueva York, examino cómo los metadiscursos acerca de lenguas y personas circulan a través de eventos discursivos y espacios sociales de diferentes escalas, que incluyen audiencias en el Congreso e investigaciones académicas acerca de NCLB, así como los ámbitos escolares en los que, en cada escuela, se ponen en práctica las políticas educativas destinadas a estudiantes clasificados como "aprendices de lengua inglesa” (English Language Learners) (Ball, Maguire y Braun, 2012).

Sostengo que los programas federales, tal como se los ha escrito, interpretado y aplicado, construyen a los estudiantes que pertenecen a minorías lingüísticas como una especie particular de sujetos educacionales (Menken, 2008), y más aún, que la construcción de sujetos ocurre por medio de prácticas gubernamentales situadas cuyo objetivo es administrar las desigualdades de clase, raza y lingüísticas características del momento actual. Por medio del examen de los detalles etnográficos de las políticas escolares y las prácticas áulicas, analizo otras prácticas estatales que diferencian y jerarquizan a los grupos etnolingüísticos en la escuela, en situaciones en que las pedagogías puestas en práctica en la clase recurren a modelos culturales acerca de minorías exitosas o fracasadas en el campo educativo. Para desarrollar este argumento, me apoyo en textos que se refieren a los registros lingüísticos como procesos históricos en curso (Silverstein, 2003; Agha, 2005; Blommaert, 2010), en la raza como condición inextricablemente vinculada con clase y lengua (Urciuoli, 1996; Alim y Smitherman, 2012); y en los poderes de Estado como "efectos" que operan en diversos escenarios y sitios (Foucault, 1998; Trouillot, 2003; Fassin, 2011).

\section{Contextos teóricos: formación de registros, la racialización del lenguaje y el poder estatal}

\section{Formación de registros}

En la última década, el estudio del poder, la desigualdad social y el lenguaje en escenarios nacionales y transnacionales se ha transformado en una arena dinámica para las investigaciones sociolingüísticas y de la antropología lingüística (Blommaert y otros, 2003; Collins, Slembrouck y Baynham, 2009; Jufferman y Van der Aa, 2013). Una línea de investigación estudia los procesos de formación de registros o "enregisterment". Los investigadores, que se centran en analizar cómo se reconocen los registros como variedades del lenguaje asociadas (estereotípicamente) con un grupo social y una gama de actividades, han podido examinar detalladamente el proceso histórico que subyace a la estratificación de las lenguas, y las contiendas y conflictos resultantes de las desigualdades entre variedades del lenguaje y los usuarios defensores de la norma (Silverstein, 2004; Agha, 2007; Blommaert, 2010). En el análisis que sigue, tomaremos en cuenta dos procesos diferenciables: por un lado, un esfuerzo conservador por estabilizar el registro del inglés estándar en su dominio social normativo; por otro, un original esfuerzo que busca ampliar los dominios de los usuarios de registros bilingües innovadores. En ambos casos, las asociaciones racializadas entre variedades del inglés o del inglés con otras lenguas son un tema central. Estas cuestiones - no demasiado atendidas por los analistas de registros (algunas excepciones son Lo y Vigouroux, 2013; Blommaert, 
1. Jim Crow fue un personaje de una obra de teatro muy exitosa alrededor de 1850 . Lo encarnaba un actor blanco (Thomas Rice) que se caracterizaba como negro exagerando todos los rasgos del estereotipo afro. El personaje era claramente burlón y despectivo. Cuando se promulgaron las leyes de segregación racial, unos años después (1876), se empezó a usar comúnmente el nombre de Jim

Crow para referirse a dichas leyes y las prácticas que instalaron.

2. Alim y Smitherman titulan "Articulate While Black" buscando realizar una referencia irónica a la frase "driving while black" ("conduciendo mientras se es negro"), que se refiere a formas discriminatorias de vigilancia en EE.UU., en las que la policía detiene un número desproporcionadamente elevado de conductores negros en controles de tránsito, lo que a menudo conduce a búsquedas y arrestos dudosos. La palabra 'articulado' se refiere a una observación hecha por políticos de nivel nacional durante el 2008, según los cuales el entonces candidato Barack

Obama era 'articulado' (para ser una persona negra), un insulto enmascarado de cumplido. El libro de Alim y Smitherman es un análisis de la capacidad de Obama para hablar una variedad de registros afroamericanos y "blanco" del inglés dependiendo de la ocasión y la audiencia, y las implicancias políticas de dicha diversidad lingüística puesta en juego por una persona con autoridad presidencial. El contraste con el estilo verbal del actual presidente Trump es revelador.

3. Collins (1999) realiza un análisis fundamentado etnográfica e históricamente de la semiótica de la controversia por el Ebonics que tuvo lugar en 2006 después de que el Oakland (California) School District propusiera usar el Inglés Vernacular Afroamericano como medio de instrucción, junto con el Inglés Americano Standard (ver también una compilación de Delpit y Perry, 1998).
2010) - se enmarcan en lo que Pratt denominó "zona de contacto" como "espacios en los que las culturas se encuentran, se entrechocan, forcejean, frecuentemente en contextos de relaciones de poder altamente asimétricas, tales como la esclavitud, el colonialismo, o sus consecuencias tal como son vividas hoy en muchos lugares del mundo" (Pratt, 1991: 34).

\section{Racialización de la lengua}

El estudio de Urciuoli acerca de experiencias de puertorriqueños en torno a lengua, raza y clase en los EE.UU. contemporáneos ofrece una valiosa teorización y análisis de las relaciones asimétricas de poder tal como son vividas actualmente en distintas sociedades (Urciuoli, 1996). Propone distinguir los discursos etnizantes de los racializantes, contraste que adoptamos en los estudios de caso que siguen. También argumenta que, fundamentalmente, los grupos son sometidos a la racialización hasta el punto de controlar su (fuerza de) trabajo, tal como sucede bajo el control colonial. Los esclavos afroamericanos en EE.UU. son el caso límite, con respecto al que se han caracterizado históricamente todos los otros grupos racializados y etnizados. Es significativo, al analizar la interacción entre raza y clase, observar que, a los inmigrantes irlandeses a EE.UU., a mediados del siglo XIX se les decía "black Irish" (irlandeses negros), cuando la mayoría era destinada a trabajos pesados, denigrantes o serviles; no así en la segunda mitad del siglo XX, cuando un número considerable había alcanzado educación y ocupaciones propias de la clase media.

Los afroamericanos tuvieron una trayectoria histórica diferente a la de los irlandeses u otros inmigrantes "voluntarios" (Ogbu, 1979), dado que en EE.UU. la esclavitud fue seguida por la segregación estilo Jim Crow, ${ }^{1}$ que sentenció a mayorías supuestamente "libres", radicadas en el sur de EE.UU., a la desposesión política, económica y cultural entre 1870 y 1960 . Uno de los resultados de esta herencia de opresión racial ha sido el fuerte estigma asociado con su variedad vernácula del inglés. Comenzando con un análisis de la innegable facilidad demostrada habitualmente por el presidente Barack Obama, de pasar de un registro a otro, Alim y Smitherman ${ }^{2}$ brindan una argumentación convincente acerca de que, a pesar de que el presidente ejemplifica lo que es ser "articulado aunque negro", las ideologías lingüísticas tanto oficial como cotidiana degradan los estilos afroamericanos de habla (Alim y Smitherman, 2012). ${ }^{3}$ Foley y Shankar, a partir del examen de las interacciones entre anglos y tejanos en las escuelas de Texas posdesegregación, y de los jóvenes sudasiáticos en Silicon Valley durante el "tech boom" de los años noventa, brindan análisis amplios de una dimensión interaccional que también abordan Urciuoli y Alim y Smitherman: cómo los hablantes racializados manejan su "perfil lingüístico" al relacionarse con las instituciones dominantes, especialmente la escuela. Los estudios de Foley y Shankar conectan directamente la clase social con modos particulares de manejar las expresiones culturales en el escenario escolar (Foley, 2008 [1990]; Shankar, 2008). Más adelante, cuando examinemos el modo en que los estereotipos acerca de las "minorías modelo" influyen en el ambiente escolar de los estudiantes migrantes multilingües, también nos referiremos a esta cuestión.

\section{Efectos de Estado}

Las políticas lingüísticas y educativas presuponen la existencia de entidades parecidas al Estado (Blommaert, 1996; Haugen, 1966; Hornberger y Vaish, 2008). Pero el estudio de cómo operan los Estados con relación al resto de la sociedad no constituye un campo de investigación claramente delimitado, especialmente en una era en la que las naciones-Estado estables, autodeterminadas, están comprometidas de modo creciente por procesos transnacionales tales como las migraciones en masa por razones laborales y los flujos de inversión globalizados (Steger, 2003; Harvey, 2005). Los antropólogos, al tratar de comprender el modo en que estos procesos afectan a los Estados, han puesto el 
foco en cómo las actividades estatales se reespacializan dentro y a través de las fronteras nacionales (Gupta y Ferguson, 2002), al tiempo que confrontan con la creciente polarización social dentro de las naciones y entre estas (Friedman, 2004). Trouillot, en un útil ensayo sobre la antropología del Estado, argumenta que hay implicaciones teóricas y metodológicas vinculadas con la combinación de actividades que descentralizan y transnacionalizan las actividades estatales (Trouillot, 2001). Desde el punto de vista teórico, es importante recordar la insistencia de Gramsci (1971) en la inseparabilidad de "Estado" y "sociedad civil", al reconocer que el estado debe conceptualizarse en más de un nivel y, metodológicamente, que el Estado está más abierto a la investigación etnográfica, ya que el mismo no se encuentra en un sitio determinado, ni institucional ni geográfico. Trouillot se concentra en el problema de la gubernamentalidad (Foucault, 1991; Fassin, 2011) para la cual no hay un sitio necesario, y propone un estudio etnográfico de los efectos de Estado, con lo que se refiere a las prácticas descentralizadas por medio de las cuales se producen subjetividades políticas y culturales en una matriz de desigualdades nacionales y transnacionales, especialmente las de raza y clase.

Varios de los efectos discutidos por Trouillot son relevantes para los datos y temas de este artículo. Primero, un efecto de aislamiento, es decir, "la producción de sujetos individualizados, atomizados, moldeados y modelados para su gobierno como parte de un 'público' indiferenciado pero específico" (Trouillot, 2001: 126). Segundo, hay un efecto de legibilidad que involucra procesos de clasificación, medición y mapeo, herramientas que harán que los individuos y poblaciones sean más gobernables (Trouillot, 2001). Entre los procesos que producen este efecto, la estandarización del lenguaje y el monolingüismo cumplen un papel primordial (Scott, 1998). En el siguiente caso, examinamos cómo la categoría "Aprendices de Lengua Inglesa" (a partir de ahora, ELL, por la sigla en inglés para English language learners), en la legislación e implementación de Ningún Niño Dejado Atrás, produce tanto efectos de aislamiento como de legibilidad para las minorías etnolingüísticas, en parte por medio de procesos de estabilización del registro de arriba hacia abajo. Tercero, hay un efecto de identificación, es decir, discursos y prácticas que realinean a los individuos con las colectividades; de este modo se producen nuevas identidades y relaciones entre grupos, al margen de la heterogénea complejidad de las historias y vidas de los individuos (Trouillot, 2001). Examinaremos cómo las respuestas diferenciales - en las lecciones escolares - a los esfuerzos por extender el dominio social de los registros multilingües ayuda a producir efectos de identificación.

\section{NCLB y la estabilización de registros: la producción de efectos de aislamiento y legibilidad}

La marca distintiva de la reforma educativa del presidente George W. Bush fue Ningún Niño Dejado Atrás, una intervención federal sin precedentes en la educación y escolarización (No Child Left Behind Act, 2001, 2002). NCLB aborda la diversidad lingüística en la educación estadounidense, enfocándose en una categoría, los "Aprendices de Lengua Inglesa" (ELL), estudiantes cuya lengua materna no es el inglés y que son evaluados como quienes necesitan instrucción o apoyo idiomático. ELL comprende una de las cuatro categorías "de riesgo", para las cuales NCLB prescribe requisitos de monitoreo especiales. Otros grupos de riesgo incluyen a los estudiantes con desventajas económicas, estudiantes de los principales grupos étnico-raciales y estudiantes con discapacidades (NCLB Public Law No. 107-110, 115 Stat. 1425, 2002). ELL es, de hecho, una categoría muy heterogénea, que incluye a aquellos con una alta pericia en el inglés y a aquellos que no la tienen; al inmigrante y al nacido en los Estados Unidos; a aquellos que viven en la abundancia de la clase media o en la pobreza (Abedi, 2004; Menken, 2008). 
4. A partir de la década de 1970, las reacciones políticas a nivel estatal a la educación bilingüe comenzaron en California y en otros estados de EE.UU. Para el año 2000, más de 30 estados tenían alguna forma de legislación que restringía la educación bilingüe. Con frecuencia, los movimientos políticos se aliaron con grupos nativistas antiinmigración o fueron guiados por ellos, y alimentaron la preocupación de los padres hispanos de que la "educación bilingüe" significaba "educación inferior y segregada". At War With Diversity (Crawford, 2001) proporciona un útil relato del movimiento y la dinámica política.
La invisibilización de la heterogeneidad en la definición de la categoría ELL resulta significativa porque desplaza el problema de las condiciones sociales en el aprendizaje escolar fuera de la discusión política. Al definir la diversidad lingüística de los estudiantes como riesgo educativo, NCLB y su implementación, paradójicamente, desvían la atención de uno de los "riesgos" para el éxito educativo convencional mejor documentados: las condiciones sociales.

Este desplazamiento puede ser examinado en dos eventos discursivos relativos a NCLB. El primero ocurrió en una sesión en el Congreso en la que se debatía acerca de la legislación y su influencia sobre los "Aprendices de Lengua Inglesa"; el segundo, durante un evento académico destinado a revisar algunos de los mismos temas. En 2007, el Congreso de los Estados Unidos realizó una serie de audiencias tituladas "El Impacto de Ningún Niño Dejado Atrás en los Aprendices de Lengua Inglesa", destinadas a evaluar la reautorización de fondos para NCLB (Congress US, 2007). Se presentó una gama de testimonios expertos: especialistas de la Oficina de Contabilidad del Gobierno sobre cómo cada Estado de EE.UU. define y evalúa ELL; directivos de las universidades sobre el mejor modo de preparar a los maestros que trabajan con estudiantes ELL y organizaciones de defensa de los hispanos acerca de problemas con la validez de los exámenes y la confiabilidad de las evaluaciones del aprendizaje de los estudiantes ELL. La siguiente información demográfica sólo es mencionada una vez en la larga sesión de audiencias en el Congreso, y no vuelve a ser retomada en futuras preguntas o comentarios: tres cuartos de los estudiantes ELL son hablantes de español y más de dos tercios de ellos son parte de familias de bajos recursos/ingresos (US Congress, 2007).

El silencio en torno a estos hechos es desconcertante. Después de tres décadas de campañas de "Sólo Inglés"4 en más de treinta estados comúnmente considerados para educación bilingüe con español, el hecho de que tres cuartos de los estudiantes ELL sean hispánicos parecería otorgar a la categoría una fuerte valencia social (Adams y Brink, 1990; Crawford, 2001). Como categoría social racializada, los inmigrantes hispanos son usualmente cuestionados como quienes tal vez no asimilen (adecuadamente) el inglés o los supuestos valores americanos dominantes. Huntington sostiene una declaración reaccionaria e influyente, ilustrativa del miedo infundido por las ansiedades sociales posteriores al 11/9 sobre los Estados Unidos y sus "otros", la cual alude tanto al lenguaje como al estatus de clase trabajadora de la mayoría de los migrantes latinos (Huntington, 2004). De Genova nos provee un análisis marxista del interjuego entre raza, clase y dominación sobre la lengua como aquello que contribuye a la subordinación laboral de los inmigrantes mexicanos, históricamente y en la Chicago contemporánea (De Genova, 2005). Urciuoli ofrece un análisis histórico de la subordinación laboral en el proceso de racialización del habla vernácula puertorriqueña en Nueva York (Urcioli, 1996). Mientras que, en Hispanophobia, Zentella analiza datos nacionales sobre el miedo al lenguaje racializado (Zentella, 1997).

Después de décadas de investigaciones que señalan que el estatus económico de las familias es la variable predictiva más contundente de un mal desempeño escolar (Jencks, 1972; Rothstein, 2004), que los dos tercios de los estudiantes ELL vivan en familias de bajos recursos parecería relevante para entender su desempeño en lengua y matemática. Sin embargo, como dijimos, el perfil económico de los niños ELL no generó más comentarios. Considero que estas problemáticas de estatus étnico-racial y clase social no provocaron ningún comentario por parte de los panelistas del Congreso o de ningún otro testimonio experto porque son asuntos ya sabidos por todos, pero que se encuentran más allá del dominio de lo "decible": el tema oficial del testimonio experto fue cómo mejorar de manera confiable las evaluaciones de los estudiantes como individuos que resultan ser aprendices de inglés; todo lo demás queda fuera del criterio que define la categoría ELL. 
Esta visión acotada en la definición de la categoría también se encuentra en los debates académicos sobre la política. En un análisis sobre investigación y políticas concerniente a ELL y "evaluación y responsabilidad", Abedi discute aspectos problemáticos de NCLB, teniendo en cuenta los requisitos de informes y pruebas que el programa demanda a las escuelas. Un área problemática fue la inconsistencia en la clasificación de LEP (ELL) ${ }^{5}$ al interior de los estados como entre diversos estados (Abedi, 2004), refiriéndose a la actual heterogeneidad existente en las poblaciones de estudiantes clasificadas como ELL. Abedi describe variados modos por medio de los cuales los procedimientos de clasificación de cada Estado redundan en diversidad al interior de la categoría, incluyendo la errónea categorización de estudiantes cuya primera lengua es el inglés como ELL, y el criterio de competencia lingüística que resulta en el constante movimiento de los estudiantes ELL con más manejo del idioma fuera de esta categoría poblacional. Ambas prácticas crean problemas de comparabilidad y desafían la posibilidad de alcanzar los objetivos de progreso promedio anual.

En su análisis acerca de la diversidad dentro de la categoría ELL, Abedi discute un estudio a gran escala (Abedi y otros, 2003) y muestra que entre los factores que contribuyen a la heterogeneidad de los estudiantes se encontraba el "historial familiar", categoría operacionalizada por el nivel educativo de los padres, una forma aproximada de referirse a la clase social. Así, el autor expone los siguientes resultados de su investigación: "las calificaciones promedio en lectura para algunos de los LEP [ELL] con padres con mayor nivel educativo, fueron mayores que las calificaciones promedio de los estudiantes non-LEP [ELL] cuyos padres habían alcanzado un menor nivel educativo" (Abedi, 2004: 5; énfasis del autor). En otras palabras, los antecedentes familiares tuvieron una mayor influencia en el desempeño escolar que el estatus de ELL per se. Al igual que en las sesiones de audiencias en el Congreso, la influencia de la clase social en el desempeño de los estudiantes es observada, mas no entra en la discusión sobre los problemas de "evaluación y responsabilidad" de ELL y NCLB. Esta omisión o desatención tanto en el Congreso como en los análisis académicos de las políticas resulta de lo más notable debido a la investigación anterior, recuperada más arriba, así como a los estudios más recientes que muestran la fuerte influencia de las condiciones socioeconómicas en el rendimiento escolar.

Esto también puede observarse en dos estudios recientes, uno enfocado en los estudiantes ELL y el otro en la pobreza infantil y las evaluaciones de alcance nacional sobre progreso educativo. Fry se centra en el enigma de interpretación respecto del rol de las escuelas en las profundas diferencias obtenidas en el rendimiento de los aprendices de lengua inglesa generando una brecha de desempeños (Fry, 2008). Está ampliamente documentado que los estudiantes ELL tienen peor desempeño en lengua y matemática que los estudiantes que no están clasificados como tales. ${ }^{6}$ Persiste, sin embargo, una pregunta sobre las causas de este fenómeno, porque los estudiantes ELL se encuentran concentrados mayormente en las escuelas donde, en promedio, todos tienen peor rendimiento en los exámenes estandarizados. $\mathrm{Al}$ analizar una serie de dimensiones con las cuales el estatus de minoría lingüística y la marginalización social son confundidos en la educación estadounidense (locación urbana vs. suburbana, tamaño de las escuelas, porcentaje de estudiantes en la pobreza), Fry discute la confusión interpretativa fundamental: determinar si realmente existe una brecha en el desempeño de los estudiantes ELL o si, en cambio, se trata de lo que podríamos denominar una brecha en el desempeño de los niños pobres pertenecientes a minorías en las escuelas urbanas (Fry, 2008).

Henwood ofrece un análisis de las variaciones de los resultados en los rankings de rendimiento de los Estados, basado en los resultados de la Evaluación Nacional de Progreso Educativo del 2010 (Henwood, 2011). Concentrándose en las variables que se corresponden con el rendimiento educativo general de los Estados, Henwood sostiene que la variable predictiva más potente de la posición de un Estado en el ranking es
5. El acrónimo “LEP” se refiere a la categoría de educación "estudiantes con dominio limitado del inglés", un término para los estudiantes cuyas lenguas maternas no eran el inglés. La etiqueta "Aprendices de lengua inglesa” (ELL) se empleó en lugar de LEP, después de que ELL fuera empleado en la legislación nacional No Child Left Behind. Los estados individualmente todavía varían en el término que usan para sus registros oficiales internos.

6. El término "servicios ELL" en Fry (2008) se refiere a una gama de servicios obligatorios ofrecidos a estudiantes que hablan idiomas maternos distintos del inglés, incluidos tutores temporales, clases de inglés como segunda lengua (ESL-English as a Second Language) o, en algunos estados, opciones de educación Bilingüe. Qué servicios reciben los estudiantes varía según el estado en particular y, por lo general, depende de la densidad demográfica de los estudiantes que comparten el mismo idioma materno en una determinada escuela o distrito escolar. Esto se discute más detalladamente en el texto. Como consecuencia de que NCLB elimina la anterior educación bilingüe para pasar a implementar un programa nacional y, en su lugar, otorga subvenciones a los estados individualmente, se han restringido los servicios de educación bilingüe, haciendo que en algunos casos haya una mayor dependecia de los programas de ESL y en otros que no haya servicios en absoluto. Los estudiantes migrantes discutidos en el caso etnográfico en este texto recibieron clases de ESL, aunque el uso del español fuera del aula de ESL era visto negativamente. 
7. Véase Agha (2005: 47-50) para un análisis más detallado de estos procesos.

8. La "Controversia del Ebonics" fue una polémica nacional que surgió cuando Oakland, California, propuso en diciembre de 1996 que el distrito utilizara el inglés afroamericano (AAE-African American English) (también conocido como “Ebonics”) como una variedad secundaria de lenguaje para instruir a los estudiantes del distrito en materias escolares, especialmente en alfabetización. A pesar de que la mayoría de los estudiantes hablaba

AAE/Ebonics en sus hogares, $y$ de que la propuesta contó con el apoyo de los maestros de Oakland y las familias de clase trabajadora de los estudiantes, el proyecto fue atacado y ridiculizado por las élites nacionales, tanto blancas como negras, y pronto abandonada. Como sostiene Collins (1999), existen analogías entre las complejas actitudes racistas mantenidas en los EE.UU. hacia el inglés vernáculo afroamericano como un medio legítimo para la educación de los niños y las pasiones políticas desatadas en oposición a la educación bilingüe español/inglés para los niños de inmigrantes hispanos de clase trabajadora. la pobreza, variable operativamente definida como la elegibilidad de esos estudiantes para becas (completas o parciales) en el comedor escolar:

casi el $60 \%$ de las posiciones de los estados en los rankings puede ser estadísticamente explicado por la porción de la población estudiantil con beca total o subsidio en los almuerzos (...) [considerando a los estudiantes cuya lengua materna es distinta al inglés] (...) la porción de estudiantes con competencias limitadas en el idioma inglés ofrece sólo un modesto coeficiente de correlación $(r=.17)$ (...) y no agrega nada en capacidad explicativa cuando se lo suma al modelo de las becas en almuerzos (Henwood, 2011: 3, 5).

Hay, así, suficiente evidencia producto de encuestas a largo plazo (Jencks, 1972; Rothstein, 2004), así como de recientes análisis de conjuntos de datos nacionales y comparativos, de que la desigualdad de clase está fuertemente implicada en el rendimiento de los estudiantes ELL en las evaluaciones estandarizadas. Podemos observar, junto con Henwood, que el estatus ELL por sí mismo no tiene una gran fuerza estadística. Esto es entendible ya que este no ocurre "en el vacío", como sugeriría el informe de Fry, así como pretendió mostrar el testimonio expuesto en el Congreso. Sin embargo, dado que las desigualdades socioeconómicas no son consideradas parte de la definición de la categoría o del criterio evaluador para los estudiantes ELL, siguen siendo dejadas fuera de los debates oficiales y análisis académicos sobre las políticas.

Para entender mejor esta invisibilización de las condiciones sociales en los discursos es útil examinar los procesos de registro en acción en la legislación de NCLB y sus implementaciones. NCLB removió la política federal de financiamiento para educación bilingüe que llevaba décadas (Woodward, 2009), y otorgó prioridad casi exclusiva al inglés estándar como el único registro de lenguaje apropiado para la educación pública en los Estados Unidos. En términos de Agha, representa un esfuerzo político en particular, dirigido a estabilizar el registro del inglés estándar monolingüe (Agha, 2005). Declarada como ley federal, implementada en todos los estados y monitoreada por políticas evaluadoras intensas y penetrantes, NCLB intenta estabilizar rasgos del repertorio ("sólo" inglés estándar, no otro dialecto social del inglés u otra lengua), características indexicales (al indicar el estereotipo del sujeto social "educado" y "exitoso" contra el "maleducado", "ignorante", "trabajador poco calificado o de "cuello azul"') y el dominio social (al proclamar el dominio universal de su uso para "todos los niños" al tiempo que dibuja fuertes límites, definidos por los exámenes estandarizados entre aquellos niños que tienen el registro y los que no lo tienen). ${ }^{7}$ Como en la polémica del ebonics, pero sin el escándalo público de humillación ritual - ya que tanto las elites blancas como afroamericanas condenaron duramente la propuesta de la Junta Directiva de la Escuela de Oakland de usar el inglés vernáculo afroamericano como una herramienta de enseñanza junto con el inglés estándar (Collins, 1999; Perry y Delpit, 1998)—, NCLB también niega que cualquier idioma o registro de idioma que no sea el inglés estándar pueda servir para la educación pública americana. ${ }^{8}$

Propongo conceptualizar la categorización de ELL y su despliegue en las prácticas evaluadoras ordenadas por NCLB en términos de dos efectos de estado relacionados entre sí. El primero es lo que Trouillot llama un efecto de aislamiento (Trouillot, 2001). Las categorías y requisitos de evaluación de NCLB definen a los estudiantes como individuos, los reagrupan en distribuciones de logros estandarizadas y oscurecen cualquier relación histórica o cultural entre los estudiantes definidos como ELL. En palabras de Trouillot, "producen sujetos individualizados, atomizados, moldeados y modelados para su gobierno como parte de un 'público' indiferenciado pero específico" (Trouillot, 2001: 126). En este caso, el "público" específico es aquel que está en riesgo educativo. 
Las cuatro categorías que componen NCLB tienen una composición social en la que resuenan históricas luchas colectivas que dieron y dan forma a la educación norteamericana - los inmigrantes, las minorías nacionales, los pobres, y 'aquellos con discapacidades' (Nasaw, 1979) —; sin embargo, ahora las identidades son repensadas como rasgos de individuos. ${ }^{9}$

El segundo efecto implica especial vigilancia y monitoreo. Para todos los estudiantes ELL, así como para los de todas las categorías de estudiantes “en riesgo", hay exámenes especialmente ordenados para evaluar el progreso anual (Adebi, 2004). Típicamente, estas evaluaciones resultan dañinas para aquellas escuelas en las que, como sugiere el informe de Fry, se concentran estudiantes pobres, racializados y hablantes de lenguas minoritarias (véase también Ravitch, 2010, para un análisis minucioso de datos nacionales y de la ciudad de Nueva York). Estas exigencias evaluadoras son combinadas con otra consecuencia de la estabilización del registro: definiciones rigurosas de lo que es un estudiante que no se ajusta a la norma, los denominados estudiantes ELL. Juntas (las evaluaciones estandarizadas anuales para las categorías "de riesgo" y la definición de lo que es un estudiante ELL) contribuyen al "efecto de legibilidad que involucra procesos de clasificación, medición y mapeo, herramientas que harán que los individuos y poblaciones sean más gobernables" (Trouillot, 2001: 126). Cabe recordar que NCLB, tanto en la legislación como en su implementación, estabiliza el inglés estándar monoglósico como el único registro que debe de ser utilizado en educación, lo que en parte termina con el financiamiento federal previamente dedicado a la educación bilingüe, pero también establece una nueva categoría, la de estudiantes ELL, para referirse a aquellos que son sujeto de evaluaciones anuales intensificadas.

Hemos analizado la creación y uso a través de una legislación nacional y su implementación, de una categoría educativa “de riesgo", la de estudiantes ELL. He sostenido que, por medio de la invisibilización de la dimensión social, asociada con la categorización de sujetos y un monitoreo intensificado de los miembros de dichas categorías, vemos los mecanismos de los efectos estatales de aislamiento y legibilidad. Dichos efectos son diversos en sus espacios de operación, pero sistemáticos en tanto herramientas del poder estatal para definir sujetos y regularlos. Ayudan a constituir dominación social por medio de regulación lingüística. En palabras de Hymes, construyen "hegemonía cultural a través del lenguaje” (Hymes, 1996 [1975]: 84). Ambos efectos de Estado están enmarcados en esfuerzos por parte del Estado federal, a través de su política educativa, de estabilizar el registro del inglés estándar.

\section{Tratamiento diferencial a estudiantes inmigrantes coreanos y mexicanos en las clases de inglés como segunda lengua (English as a Second Language - ESL): dominios sociales del registro y efectos de identificación}

Volvamos nuestra atención ahora a dos estudios sobre dos escuelas y espacios áulicos que nos recuerdan que el terreno lingüístico de la educación es negociado, sea en escenarios locales como de mayor escala. Estos estudios proveen evidencia etnográfica de otro proceso de registro: el esfuerzo que hacen los niños inmigrantes por expandir los dominios sociales de registros en idiomas distintos al inglés mientras que, significativamente, reciben respuestas desiguales por parte de las escuelas a dichos esfuerzos. Sostengo que estas respuestas desiguales resultan, respectivamente, de la interacción entre diferencias lingüísticas y modelos culturales construidos acerca de estudiantes pertenecientes a minorías, y que esto provee evidencias, en forma de prácticas lingüísticas locales, de un tercer "efecto de Estado".
9. Como McDermott, Raley y Seyer-Ochi han sostenido recientemente en un ensayo sobre clase, raza y riesgo en escolaridad norteamericana, "en todos lados el riesgo genera reacciones de los individuos, pero rara vez, respuestas colectivas" (McDermott, Raley y Seyer-Ochi, 2009: 106) y siguen diciendo que "las escuelas americanas funcionan sobre el riesgo y la competencia. Es el hecho primordial para niños que van a la escuela en un mercado diseñado para que unos pocos manden sobre las mayorías y en una cultura que hace a los deseos y logros dependientes de las faltas y falencias de otros (Henry, 1963; Varenne y McDermott, 1998)" y advierten que "un énfasis facilista a la raza, la clase, y las discapacidades para el aprendizaje, vistos como rasgos, obscurece las demandas invisibles de la política económica, por parte de aquellos que, desde posiciones y perspectivas absolutamente parciales, están preocupándose, operando y hablando sobre la misma, y creando estrategias para manipularla" (McDermott, Raley y Seyer-Ochi 2009: 109; énfasis agregado por el autor). 
Lo primero a lo que debemos atender es lo siguiente: en un estudio sobre estudiantes coreanos en una escuela primaria de los suburbios al norte del estado de Nueva York, Hong describe el modo en que la maestra de la clase de ESL donde la autora realizó su investigación respondía de formas diversas a la lengua materna de sus alumnos (Hong, 2006).

A pesar de que la política de la escuela era de "Sólo Inglés", y las clases de ESL una herramienta en la implementación de esa política, la maestra de esta escuela —a la que nosotros denominaremos Primaria Farmer- habilitaba momentos especiales para que los estudiantes pudieran hablar coreano entre ellos; ella llevaba libros e imágenes coreanas e incorporaba a su clase y a lo que enseñaba múltiples referencias a prácticas culturales coreanas. Ella misma se dedicó a aprender algunas palabras y frases en coreano. En resumen, autorizó el uso del idioma coreano entre estudiantes para ciertos espacios y tiempos escolares. Observamos que, en consecuencia, los niños usan el coreano colaborativamente para participar de las clases, y muestran una profunda comprensión metapragmática en ambas lenguas.

(1) Coreano e inglés en uso en clases de ESL en la escuela Farmer $1 \mathrm{M}$ (maestra): (leyendo el libro) “Aekyung fue a la escuela el resto de la semana y trató de ignorar las burlas del resto de los niños. El domingo, la tía de Aekyung, Kim, vino de visita. Acababa de volver de Corea con muchos regalos para toda la familia y un sofisticado vestido para Aekyung.

‘¿cómo están las cosas en Corea?' preguntó Padre”

2M: ¿cómo se llama esto? (señalando un dibujo en el libro que incluye una nena usando un vestido tradicional coreano)

3Dan: Uh...

4Ming: Hanbok

5Kim: Hanbok

6M: Hanbok ¿recuerdan que usamos eso en la obra de teatro que hicimos el año pasado?

7Ming: ¿Cómo... cómo... sabes... en inglés? Quiero decir... eso inglés.

8M: ¿Que cómo lo sé?

9Ming: Sí.

10M: Porque vos me lo enseñaste, cuando me trajiste el vestido, me enseñaste que se llama Hanbok.

11Ming: No... (hablando en coreano camina hacia su hermana, Hana, que está sentada del otro lado de la mesa y le habla por lo bajo).

12Hana: ¿cómo sabes... digo... cómo decir Hanbok en inglés?

13M: Creo que es la misma palabra, la misma palabra. No hay una palabra en inglés, a menos que quieras decir vestido sofisticado, Hanbok.

14Ming: Ah, ¿es lo mismo?

15M: Creo que sí, que significa vestido sofisticado.

(7 de enero de 2005, en Hong 2006: 90-91)

Varios elementos llaman la atención en este extracto. Primero, la maestra les lee una historia sobre Corea a los estudiantes de ESL, es decir, a los estudiantes de inglés como segunda lengua. Adicionalmente, cuando ella les pregunta el nombre del vestido y ellos responden en coreano, ella decide incorporar la palabra coreana, hanbok, a sus preguntas subsiguientes (en el turno de habla 6). Cuando una de las estudiantes, Ming, comienza a frustrarse con las preguntas que le estaba haciendo a la maestra (por un

10. Ming quería saber el término en inglés; la maestra piensa que Ming está preguntando cómo es que la maestra sabe el término coreano

(el énfasis es puesto por Collins. Va en el cómo porque la confusión reside ahí entre el cómo se dice y el cómo se sabe. Nota de Traducción). aparente malentendido), ${ }^{10}$ se vuelve hacia su hermana, Hana (en el turno de habla 11) y le pide en coreano que le explique la pregunta a la maestra. Hana lo hace y la maestra ofrece una respuesta (turnos 12 y 13). Como Hong comenta sobre este intercambio, los estudiantes no sólo están leyendo sobre Corea y discutiendo palabras coreanas, están también usando su lengua materna para organizar entre ellos las tareas de interpretación, al servicio de la clase. 
En el estudio de Hong sobre el uso de los niños del idioma coreano, del inglés y otras lenguas en sus hogares y con sus pares, encontramos que el pasaje de un código a otro era algo común. Los niños hablaban coreano, otras lenguas del este asiático (vietnamita o japonés) y ocasionalmente inglés con sus padres (Hong, 2006), mientras que con sus hermanos y amigos, a la hora de jugar, alternaban entre opciones que variaban sensiblemente de acuerdo con quiénes eran los interlocutores. Cuando los niños migrantes del estudio en cuestión jugaban con niños coreano-americanos, notaban diferencias en las competencias en el coreano o el inglés, respecto de sus pares nacidos en Estados Unidos: "Hana (...) describió a unas de sus compañeras de clase con las que jugaba y hablaba en inglés, como una coreana 'que no habla muy bien en coreano"' (Hong, 2006: 64). A la inversa, los niños se adaptaban a niños recién llegados que no hablaban demasiado inglés. Kim, un niño retratado en el estudio, hablaba coreano con sus padres e inglés con su hermano mayor. Sin embargo, cuando llegó un nuevo amigo que hablaba poco inglés, Kim y él negociaron códigos: el amigo prefería coreano; Kim, inglés, pero ambos aprendieron a ajustarse a los recursos lingüísticos del otro en cada específico contexto de juego (Hong, 2006). Debemos señalar que tanto los padres como los niños consideraban mantener el uso del coreano, a la par que el aprendizaje del inglés, como un objetivo importante.

Sugiero que tenemos aquí evidencia para pensar al inglés y al coreano como opciones en un repertorio multilingüe de registros (Silverstein, 2003; Blommaert, 2010) que tiene lugar en escenarios domésticos y de pares. Es más, cuando los estudiantes usan y son habilitados a usar el coreano en determinados escenarios escolares - incluyendo la clase de ESL, pero no limitándose a ese espacio-, ellos están extendiendo el dominio social del registro. Es decir, están extendiendo el registro multilingüe de inglés y coreano, desde escenarios domésticos y de actividades organizadas entre pares, a escenarios escolares. Al hacerlo, están expandiendo el dominio de destinatarios previstos, $o$ futuros usuarios, del repertorio de registros. A partir de la descripción de Hong, surge que las actividades organizadas entre pares podrían funcionar como bisagra para estos esfuerzos. Esto es lo que hay en común entre los juegos grupales fuera de la escuela, el recreo, la hora de la merienda en la escuela y, al menos, un aspecto del hecho de que se permita el uso del coreano en la clase: Hana y Ming recurriendo juntas al coreano y al inglés para organizar su interacción con la maestra.

Esta situación de relativo acuerdo lingüístico difiere considerablemente de lo que descubrimos mi asistente y yo cuando investigamos cómo les iba a los niños migrantes hablantes de español en la misma región (Collins y La Santa, 2006; Collins, 2012). Uno de los espacios en los que realizamos nuestra investigación era una escuela de las afueras similar a la del estudio de Hong — ambas escuelas recibían predominantemente familias de clase media, presentaban buenos resultados en las evaluaciones estandarizadas y una currícula de "Sólo Inglés"-. En la escuela primaria en la que realizamos la investigación, a la cual llamaré Primaria Sanderson, muchas de las maestras cuyas clases observamos dijeron que sabían hablar español. Sin embargo, las maestras de Sanderson también se apresuraban a aclarar que sentían que el español no debía ser usado con sus estudiantes inmigrantes mexicanos, y que se esforzaban por mantenerlo fuera de las actividades escolares, ya que veían el uso de este idioma como un potencial obstáculo al aprendizaje del inglés. En palabras de una de ellas, el español era una fuente de "problemas con el lenguaje" en el aprendizaje escolar (para más datos y análisis véase Collins, 2012).

En las clases de ESL que observamos, no se aceptó el uso de la lengua materna de los niños. Los dos fragmentos que siguen lo ilustran claramente. En (2) un estudiante, MV, le pregunta a la maestra sobre una imagen y su respectiva palabra, en una actividad de construcción de vocabulario en la cual debían identificar palabras y hacer un círculo en torno a imágenes de animales. Como podemos ver, toda la comunicación es en inglés: 
11. Nota de traducción: Todo este diálogo está en español en el original. La única diferencia es que el autor lo traduce al inglés para sus lectores, lo cual es innecesario en esta versión

12. Esto fue estrictamente así en la media docena de clases ESL que observamos.

13. Nota de traducción: En español y bastardilla en el original.
MV pregunta ¿esto es elefante?; la maestra toma en cuenta la pregunta y manda a MV a volver a seguir con su tarea hasta que la termine.

(2) Recibiendo consignas en inglés en clases de ESL en la primaria Sanderson

(MV se acerca a la maestra, M)

M: claro que sí, tráelo (a MV)

MV: ¿esto es elefante?

M: Eh, no...TERMINA y después vení a verme nuevamente.

MV: Ok.

Durante esta misma clase, nuestra asistente en el proyecto de investigación (AL), bilingüe fluida, había estado trabajando con un estudiante en una actividad similar de vocabulario. Ella planteaba sus preguntas en inglés, pero permitía al estudiante contestar con preguntas o respuestas en español o inglés. En un momento, MV y una nena nueva se acercaron a Amarylis (AL) y MV presentó a la niña, como se ve en el extracto (3):



En este extracto (3), podemos ver que los estudiantes de Sanderson - así como los de Farmer - tienen conocimiento tanto metapragmático como metalingüístico de sus lenguas maternas, conocimiento que usan para organizar la interacción durante la clase. MV presenta a su nueva compañera y realiza observaciones acerca de las diferencias en la pronunciación del nombre Laura en inglés y español ([lawra] vs. [lorə]). El intercambio se asemeja al ejemplo (1), en el cual se representaba el uso del coreano en Farmer, en el hecho de que muestran que, cuando el uso de la lengua materna junto con el inglés es habilitado interaccionalmente de acuerdo con las características demográficas de los hablantes, los niños usan ambas lenguas. El español, sin embargo, no fue permitido nunca como parte de la clase en Sanderson. El patrón predominante en Sanderson fue como lo que se muestra en el ejemplo (2), es decir, con interacción restringida al inglés. ${ }^{12}$

Al igual que los niños coreanos del estudio de Hong, los niños migrantes hispanohablantes usaban inglés, español y otras lenguas en escenarios domésticos y no escolares. Dependiendo de la familia, ellos hablaban triqui, una lengua indígena-mexicana, español, o inglés, en las interacciones con sus padres, y español o inglés con amigos y hermanos. De similar modo, así como los padres coreanos de clase media, los padres mexicanos de clase trabajadora también veían como algo valioso que sus hijos aprendieran tanto inglés como español. Como me dijo uno de ellos, en palabras que resonaban en el punto de vista de otros padres triqui, los niños necesitaban del inglés para leer y escribir y hablar con sus amigos. ${ }^{13} \mathrm{~A}$ la vez, el español también era necesario para que sus niños pudieran interactuar con nuevos inmigrantes, quienes han estado llegando a la región durante más de dos décadas y entre quienes, más allá de cuál fuera la lengua materna, el español ha venido funcionando como una lengua franca.

Durante nuestro estudio, enfocamos nuestro trabajo en el hogar de dos familias, a una de las cuales llamaremos Valdez (un seudónimo). En el momento de nuestro estudio, los niños Valdez, acerca de los que se habló en los ejemplos anteriores y a continuación, hablaban español y triqui con fluidez y estaban aprendiendo el inglés. Su socialización lingüística informal involucró el uso de múltiples idiomas para negociar el mundo social (Zentella, 2005). Amarylis, la asistente de investigación, y yo habíamos trabajado en 
la casa de la familia Valdez, brindando clases de idiomas tanto a los adultos como a los niños. Durante estas actividades estaba usualmente presente José, el hermano de 12 años de edad de Sandra y Mariana. En muchas ocasiones, él traducía entre triqui y español; por ejemplo, cuando su madre, que sólo hablaba triqui, quería decirnos algo a Amarylis o a mí. Su traducción respondía a una situación determinada: nosotros hablábamos español, ella (la madre), triqui, y él mediaba alternando entre las dos lenguas.

En muchas ocasiones, José se sumó a la lectura o a cualesquiera fuera la actividad de clase que estuviéramos llevando adelante con sus hermanas Sandra y Mariana. A veces, cuando las chicas tenían dificultad para recordar el nombre de alguna imagen o ítem listado en nuestro libro bilingüe español/inglés, él ofrecía ayuda, sugiriéndoles a sus hermanas respuestas en español o en triqui, su lengua materna. Mostramos un ejemplo de esto en (4). Sandra había estado nombrando ítems en un libro de imágenes; cuando ella titubeaba, pareciendo no saber una palabra, José ofrecía ayuda sotto voce:

(4) José ayudando durante una clase en casa de inglés y lectura. ${ }^{14}$

1 SV: The... [la...]

$2 \mathrm{~J}$ : (¿chubia?)

3 SV: The (butterfly??) [¿La (mariposa?)]

4 AL: Tu le estás diciendo en triqui**

5 J: Le estoy diciendo la word como mariposa.**

$6 \mathrm{AL}:$ ¿En triqui?

7 J: Sí.

$8 \mathrm{AL}:$ ¿Cómo se dice?**

9J: ¿En Triqui? ... Chubia, chubia.**

$10 \mathrm{AL}:$ Ok.

El contexto de este extracto es que Sandra está en una clase con Amarylis, y José se acerca y empieza a participar. Pero al hablarle a su hermana en un susurro y con el cambio al triqui en la línea 2, José se involucra en lo que Goffman llamó un cambio en el "posicionamiento" (footing) (Goffman, 1981). Es decir, él modifica el contexto, lo que es a su vez un cambio en la configuración de las participaciones: partiendo de una clase conducida en español e inglés que involucraba a Sandra y Amarylis, se transforma velozmente en un ejercicio de estímulos, que envuelve diferentes participantes, José y su hermana, una momentánea actividad detrás de escena entre hermanos, inserta, como tal, en el género mayor de "la clase". En la línea 4, Amarylis nota el cambio de lengua y le pregunta a José al respecto. En la línea 5, él explica su estrategia: proveer una palabra triqui para el ítem en el texto en inglés, es decir, proveer estímulos multilingües para ayudar a su hermana hablante de triqui y español, a identificar el lexema inglés "butterfly".

Los niños también usaban el español en la escuela cuando otros hablantes de español estaban disponibles, fueran los ayudantes bilingües de las maestras, asistentes de investigación visitando la clase, hermanos o sus pares, compañeros de clases y juegos. Sugiero que - al igual que con los estudiantes coreanos en la primaria Farmer- tenemos evidencia inicial para pensar al inglés y al español como opciones de registro en un emergente repertorio de registros. Cuando los estudiantes usan tanto el inglés como español en el marco de la escuela incluyendo, pero no limitándose a las charlas durante la clase de ESL, están intentando extender el dominio social del repertorio bilingüe de registros en el escenario mayor del norte del estado de Nueva York.

Por alguna razón, sin embargo, la diferencia etnolingüística mayor que existía en el caso de los estudiantes coreanos en Farmer — donde las maestras, incluyendo las de ESL, no sabían hablar coreano- era vista como un recurso para ser usado en el aprendizaje del inglés, mientras que la diferencia etnolingüística menor respecto de los estudiantes
14. Los turnos de habla con dos asteriscos al final (**) están idénticos al original. 
15. Nota de traducción: En español en el original. mexicanos en Sanderson —donde las maestras sí sabían hablar español— era vista como un impedimento al mismo aprendizaje. La pregunta es por qué ocurrió esta diferencia en el juicio práctico (Bourdieu, 1998). Exposing Prejudice de Urcioli, incluye un análisis sobre lengua, raza y clase, que nos puede ayudar a desentrañar este asunto (Urcioli, 1996). En su análisis, Urcioli se centra en los discursos racializantes y etnizantes - modos de caracterizar grupos de personas, atados a proyecciones sus familias y comunidades, las formas de lenguaje que usan, y sus probabilidades de adquirir la identidad estadounidense normativa o "sin marcas", un ideal simbólico en el cual los usos del lenguaje y la clase social son características centrales-. De acuerdo con la autora, racializar y etnizar discursos son formas de manejar la diferencia, de señalar simbólicamente a aquellos que no son blancos, de clase media, hablantes de inglés estándar, pero haciéndolo de una forma gradual.

Los discursos etnizantes son los que presentan la diferencia como algo seguro, contenido dentro del dominio social de lo apropiado, y que, de algún modo, brinda las bases para la movilidad social. En dicho modelo discursivo, los coreanos pueden hablar otras lenguas, pero se puede confiar en que aprenderán inglés; provienen de familias presumiblemente estables y comunidades respetuosas de la ley; quizás más crucial todavía es que se presupone que su movilidad social será ascendente: serán clase media (Lee, 1996; Park, 1996).

Los discursos racializantes son los que representan la diferencia como algo peligroso, que ocurre por fuera del dominio social de lo apropiado, y referidos a la clase incorregiblemente trabajadora o pobre. En este modelo discursivo, los mexicanos no sólo hablan otra lengua, sino que además se teme que no aprenderán o se resistirán a aprender inglés; ellos no vienen de familias y comunidades estables, sino de barrios $^{15}$ descontrolados. No se presume que vayan a ascender socialmente, en tanto son predominantemente clase trabajadora, como lo han sido por muchas generaciones de migración laboral (De Genova, 2005).

Como la descripción de Hong de la relación casa-escuela certifica, los estudiantes migrantes coreanos de clase media en clases de ESL en la escuela Farmer eran vistos como minorías modelo. El personal de Farmer y el programa ESL valoraban el idioma y cultura que los niños traían de sus hogares: "las herencias cultural y lingüística de los estudiantes son consideradas como recursos valiosos para facilitar la adquisición del inglés, así como también para conectar a los hogares con la escuela en el transcurso del año escolar" (Hong, 2006: 60). La maestra de ESL alentaba a los padres de los alumnos a participar en las clases, y el programa ESL organizaba numerosas "celebraciones multiculturales" en reconocimiento de los logros de los estudiantes coreanos en su aprendizaje (Hong, 2006). En resumen, su diferencia idiomática era vista como un recurso para el aprendizaje y, así, era habilitada en ciertos escenarios escolares.

En cambio, los estudiantes migrantes mexicanos de clase trabajadora del programa ESL en Sanderson no eran vistos como minorías modelo, sino como minorías racializadas. La directora de la escuela respaldó cálidamente el ethos del trabajo duro y la familia unida que ella y el personal de la escuela percibían como rasgos de las familias inmigrantes mexicanas, pero ella y su personal también decían que, debido al idioma, los padres no eran capaces de ayudar a sus estudiantes con la tarea. En el curso de nuestras visitas a las clases y entrevistas con la maestra, escuchamos el discurso acerca de los "problemas de lenguaje" por parte de la directora, de muchas maestras de las clases regulares y de un especialista en lectura. Nunca estuvo del todo claro hasta qué punto dichos problemas tenían que ver con la dificultad de la cruza de lenguajes y hasta qué punto eran sospechadas otras categorías de patologías lingüísticas. Dos de los niños inmigrantes descriptos como algunos de los que tenían dichos problemas eran además hablantes de inglés como su primera lengua. ${ }^{16}$ La maestra de ESL reconocía su consi-
16. Este es un problema frecuente de error en la clasificación lingüística (Abedi 2004; Menken 2008). 
deración por los estudiantes, al ser ella misma una inmigrante, $\mathrm{y}$ al sentir que el esfuerzo de los niños por aprender inglés mientras lidiaban con las tareas escolares regulares no era recibido con mucha empatía o apoyo por parte de la escuela. Pero, aparentemente, ella no estaba autorizada o capacitada para ver "las herencias cultural y lingüística de los estudiantes [...] como recursos valiosos para facilitar la adquisición del inglés" (Hong 2006: 60). En cambio, su diferencia lingüística era vista como un obstáculo al aprendizaje escolar y su uso no estaba permitido en ningún escenario escolar. La excepción, aparentemente, hace a la regla: como analizo más en profundidad en otro lado (Collins, 2011, 2012), los ayudantes de asistentes docentes en Sanderson - quienes resultaban ser hablantes bilingües de inglés-español- se inclinaban por apelar al conocimiento de español de los niños para trabajar en las actividades de alfabetización o matemática. Sin embargo, la única vez que comenté algo sobre esto a la maestra responsable del curso, dejó clara su desaprobación de esta práctica. Comparando a los niños coreanos en Farmer con los niños mexicanos en Sanderson, los esfuerzos de un grupo por extender el dominio social de su registro multilingüe encuentran un éxito calificado; mientras que los esfuerzos del otro grupo se topan con la resuelta oposición de aquellos en posiciones de autoridad.

Al pensar esta problemática — de cómo los estereotipos sobre minorías "modelo" y las que no lo son encuentran apoyo en las clases de ESL-, debemos considerar la posibilidad de que estemos ante procesos de interacción diferenciados por clase social. Sabemos que los estudiantes coreanos venían de familias educadas de clase media y que la primaria Farmer realizó todos los esfuerzos necesarios para comunicarse con ellas, incluyendo la traducción al coreano de los anuncios escolares destinados a los padres. No sabemos, por otro lado, si los estudiantes coreanos procuraban usar el coreano sólo en las situaciones permitidas por el personal de la escuela, mientras que sí tenemos el informe de Hong de que los niños eran vistos como "buenos estudiantes". Como Hong dice respecto del niño mencionado más arriba, Kim, "su vida social en la escuela concuerda con los valores culturales en los que se hace énfasis en el hogar. Por ejemplo, él era reconocido como un estudiante educado y amable, respetuoso con sus pares y maestras" (Hong, 2006: 118). Tenemos también evidencia etnográfica, basada en nuestro extenso estudio sobre los migrantes mexicanos en el norte del estado de Nueva York, de que las familias de clase media tendían a diferenciar más tajantemente la casa y la escuela como dominios para el español y el inglés respectivamente, mientras que los mexicanos de clase trabajadora que entrevistamos veían el aprender inglés como el propósito principal de la escolaridad, pero por otra parte, reportaban mayor superposición de dos o más lenguas, en tanto ellos y sus niños se movían entre interlocutores y actividades en triqui, español e inglés (véase Collins y La Santa, 2007).

Esta aparente disposición por clase social a la apertura o cautela en el despliegue de un repertorio multilingüe es presentada en otros estudios sobre escolaridad y minorías étnicas y etnolingüísticas (en un temprano estudio de Scollon, 1981). Shankar (2008), en su estudio sobre migrantes surasiáticos en Sillicon Valley, describe cómo los participantes de la investigación de clase media alta evitaban usar en escenarios escolares los idiomas que hablaban en sus hogares excepto durante ocasiones especiales como "El Día Multicultural”. En cambio, los participantes de clase trabajadora usaban abiertamente en la escuela el idioma del hogar, mezclando inglés con urdu $\mathrm{u}$ otras lenguas, en una práctica bilingüe entre pares que veían como un distintivo de identidad étnica. Shankar cuenta que el personal de la escuela que los vio haciendo esto juzgó negativamente dichas prácticas, dado que veían el uso de idiomas distintos al inglés como evidencia de que se trataba de estudiantes pobres "que tenían problemas con el inglés". Dichos estudiantes eran, también, frecuentemente aquellos que tenían dificultades para mantener el "estereotipo de minoría modelo", aunque Shankar atribuye esta dificultad más a un rango de condiciones asociadas a la clase social $^{17}$ que a la inteligencia o a la motivación individual de los estudiantes.
17. Esto incluye la falta de inglés en el hogar, el desconocimiento por parte de los padres de las consecuencias de las decisiones de la escuela y la presencia de un mercado laboral de puestos técnicos (de rango medio/greycollar) que redujo la necesidad de gran distinción académica. Su idea central era señalar que lo de las "minorías modelo" era un ideal específico de clase aplicado estereotípicamente a todos los estudiantes surasiáticos. 
18. Para Foley, la cultura capitalista es fundamentalmente "acción comunicativa” (Habermas, 1987), y la(s) cultura(s) de clases son "discursos performativos situados" (Foley, 1990: 178-81, 192-94), representados y aprendidos en muchos lugares, incluyendo el salón de clase. Estas cortan transversalmente e informan la presentación y reproducción de las identidades étnicas.
19. Cómo circulan estos modelos y con qué efectos es algo que requiere más investigación etnográfica. Su crítica, como nos muestran investigadores como Lee (1996) y Shankar (2008), requiere un análisis que tenga en cuenta la clase social y cómo está presente en la presentación que hacen los estudiantes de ellos mismos y de su lenguaje, y en las respuestas del personal de las escuelas a ello. Requiere, a su vez, de análisis de los desarrollos y rupturas a lo largo de la historia, en los cuales se produjeron y evidenciaron rearticulaciones entre raza, clase y lenguaje.
Los descubrimientos de Shankar coinciden con el mucho más temprano estudio de Foley (2008 [1990]) sobre clase, raza y relaciones comunicativas en una escuela secundaria en el sur de Texas. Foley sostiene que hay disposiciones interaccionales específicas de clase que atraviesan los límites étnicos: los estudiantes de clase media -fueran "anglos" o "tejanos" - eran más cuidadosos de no violar las normas de la escuela u otras costumbres sociales; mientras que, por el otro lado, era más probable que los estudiantes de clase trabajadora burlaran las normas más pública y abiertamente. ${ }^{18} \mathrm{Su}$ comportamiento provocaba la formulación de estereotipos raciales negativos acerca de los "estudiantes problemáticos", al igual que en el estudio de Shankar. En resumen, queda todavía mucho por investigar sobre cuáles son los desencadenantes comunicacionales precisos de la estereotipación, sea negativa o positiva.

Tenemos, no obstante, evidencia etnográfica que sugiere que existen las diferencias de clases (sociales) en prácticas comunicativas multilingües y que interactúan con las expectativas de la escuela de los modos que pueden dar lugar a la creación de modelos culturales que enmarcan diferencialmente a los estudiantes de minorías lingüísticas de clase media y de clase trabajadora. Tenemos evidencia de la relación entre el estatus de clase y las prácticas de racialización aplicadas a las minorías lingüísticas. Sugiero que el estereotipo cultural de la "minoría modelo" puesto en práctica recurrentemente, todos los días, en las clases y otras interacciones en la escuela, comprende un tercer efecto de Estado. Esto es lo que Trouillot llama efecto de identificación: procesos que alinean individuos atomizados dentro de colectividades, en el caso en cuestión, dentro de una jerarquía de minorías etnolinguísticas etnizadas y racializadas, con repertorios multilingües más y menos aceptados. Dicho alineamiento otorga una identificación en el paisaje político-cultural de NCLB, una identificación como parte de aquellas minorías lingüísticas que, con todo, sobresalen en la escuela, o como parte de aquellas que están "en riesgo" de fracasar.

En caso de que parezca demasiado forzada nuestra propuesta de conectar estereotipos culturales de circulación local a procesos estatales, deberíamos tener en cuenta que el estereotipo de la "minoría modelo" surgió en respuesta a los movimientos por los derechos civiles de los años sesenta (Lee, 1996; Shankar, 2008). Estos movimientos articularon demandas colectivas de reparación a los gobiernos estatales y nacionales a lo largo de las décadas del cincuenta y el sesenta. Basándose (principalmente) en reclamos de afroamericanos, latinos y nativo-americanos de clase trabajadora, lograron construir argumentos sobre la opresión histórica y el tratamiento desigual en las escuelas, el mercado laboral y otros sectores de la sociedad. En oposición a este trasfondo histórico - es decir, en el contexto de una reacción de la política nacional a los grupos etnorraciales disidentes-, los inmigrantes asiáticos fueron representados como una alternativa, esto es, como una minoría modelo mayoritariamente de clase media y tendiente al ascenso social (Lee, 1996). ${ }^{19}$

\section{Conclusión}

En las páginas precedentes he analizado "la construcción de aprendices de lengua inglesa", construcción que tiene lugar por medio de procesos que gestionan poblaciones y articulan diferencias, al tiempo que generan sujetos sociales en relación con diferencias que a un tiempo son presentadas como oscuras y vueltas legibles; lo que produce sujetos individuales aislados, tanto como identifica nuevas colectividades jerarquizadas etnorracialmente. En este análisis, ha sido importante examinar metadiscursos sobre lenguajes y personas y cómo estos circulan en espacios y tiempos determinados. El concepto de registro ha sido relevante para entender cómo se hacen y deshacen determinadas asociaciones entre usos del lenguaje y tipos sociales y cómo dichas asociaciones adquieren legitimidad y generan consecuencias sociales, o cómo son rechazadas y 
ridiculizadas. Cuando el inglés estándar es reafirmado como el único registro para la educación, quienes son hablantes de otras lenguas — cualquiera sea la robustez de su repertorio multilingüe - son juzgados como sujetos “en riesgo". Si la construcción de la relación entre lengua y sociedad fuera otra, por ejemplo, una en la cual los individuos y grupos políglotas fueran considerados normales, entonces, aquellas personas y grupos que hablaran "sólo inglés", serían vistos como aquellos “en riesgo".

En los casos que hemos examinado, el concepto de formación de registro ha provisto las herramientas para analizar la forma en que las instituciones articulan las lenguas en relación con sus hablantes, y cómo los hablantes, en la plurilingüe variedad de sus circunstancias, inician repertorios de registros multilingües, en un intento por reclamar para sus diversas voces espacios institucionales más allá de la vida doméstica. En el caso analizado, he sostenido que tanto las políticas federales "de arriba hacia abajo", como los esfuerzos "de abajo hacia arriba" por crear registros multilingües generan efectos de Estado.

La propuesta conceptual de Trouillot de los efectos de Estado se apoya en una visión del Estado como central para mantener o disputar la hegemonía capitalista, pero no como algo centrado en algún espacio institucional o geográfico específico. Su concepción de hegemonía concuerda con la insistencia de Hymes respecto de que

El lenguaje ha sido el principal medio de control de la hegemonía cultural en los Estados Unidos. La estratificación de clase y los supuestos culturales sobre el lenguaje, convergen en la escuela para reproducir el orden social. Una función tácita del sistema educativo es inculcar inseguridad lingüística, discriminar lingüísticamente, encauzar a los niños de modos que tengan un componente lingüístico integral, al tiempo que se presenta al sistema como si fuera abierto y justo para todos (Hymes, 1996 [1975]: 84).

A diferencia de Hymes, que escribió sobre el período previo a los años setenta, Trouillot lidia con la noción de Estado como parte de un sistema global, y teorizando diferentes, descentrados y "globalizados" mecanismos de hegemonía. Él está, de todos modos, interesado - como lo estaba Hymes - por cómo la relación "Estado/sociedad” regula las desigualdades de clase y raza. La visión de Trouillot del Estado como "des-centrado" nos invita a investigar los "efectos" que emergen tanto de las políticas gubernamentales formales, de la interacción cotidiana de prácticas lingüísticas multilingües, y los estereotipos culturales sobre minorías modelo. Estos estereotipos pueden ser comprendidos en lo que Hymes denominó “supuestos culturales sobre el lenguaje” (Hymes, 1996 [1975]).

Los esfuerzos, desarrollados más arriba, de los niños en las escuelas pueden también ser vistos como parte de lo que Silverstein (2003) ha analizado como "minorías lingüísticas re-energizadas”. Tales minorías, que usan frecuentemente tecnología digital que permite la comunicación cotidiana y consumos culturales a escala transnacional, resultan un desafío para los actuales esfuerzos de los Estados Unidos por regular sus poblaciones. Las prácticas multilingües y multidialectales generadas por dichas minorías lingüísticas, tanto locales como globales en sus recursos lingüísticos y audiencias relevantes (Shankar 2008; Blommaert 2010; Alim y Smitherman 2012), se encuentran con "nerviosos esfuerzos por reprimir" por parte de lo que "sería un Estado-nación asimilacionista como los Estados Unidos". Silverstein interpreta el rechazo en los años noventa al ebonics como registro para la educación pública como algo similar al contemporáneo rechazo al plurilingüismo por parte del “sólo inglés” (Silverstein, 2003: 548).

El rechazo a los dialectos sociales no-estándar y a las "lenguas extranjeras" nos recuerda que lengua, raza y clase son factores que están íntimamente conectados tanto en la sociedad como en las escuelas. Estos dialectos sociales no estándar son básicamente los registros vernáculos de las mayorías trabajadoras multirraciales. 
Las lenguas "extranjeras" son generalmente experimentadas como el discurso de los migrantes, y como Sassen nos recuerda en su estudio histórico-comparativo, los migrantes, típicamente, vienen a hacer el trabajo pesado, peligroso o servil de la sociedad (Sassen, 1997). Ningún Niño Dejado Atrás trata discursivamente sobre igualdad de oportunidades - "Ningún niño dejado atrás" es la mítica persecución del sueño americano de seguridad y prosperidad, a través de la educación-. En la práctica, o quizás más precisamente, en efecto, mientras aparece como "abierto y justo para todos", NCLB se trata de la organización y el desarrollo de un régimen de evaluaciones que vuelven legibles los diferentes resultados educacionales de estudiantes y escuelas: los que tienen o no tienen recursos económicos; los que forman parte de o sirven a los racialmente privilegiados o desfavorecidos. El desafío es conectar las dinámicas de clase con las de las prácticas de racialización y, a su vez, ambas con la valorización o desvalorización de las lenguas en las escuelas y, más ampliamente, en la sociedad (Urcioli 1996; Alim y Smitherman 2012; Rampton, Harris, Collins y Blommaert, 2008). Mi propuesta es que el estudio del "enregisterment" (Agha, 2007) ofrece una perspectiva para analizar los procesos de diferentes escalas por medio de los cuales las jerarquías lingüísticas son estabilizadas y desafiadas, al tiempo que el estudio de los efectos de Estado ofrece una valiosa ventana al asunto de la gubernamentalidad contemporánea. En paralelo, estas perspectivas teóricas pueden ayudarnos a investigar cómo, en el siglo veintiuno, "la estratificación de clase y los supuestos culturales sobre el lenguaje convergen en la escuela para reproducir el orden social", un proceso en el cual "el lenguaje es el medio principal". 


\section{Q Bibliografía}

" ABEDI, Jamal. 2004. "The No Child Left Behind Act and English Language Learners: Assessment and Accountability Issues". Educational Researcher, 33(1): 4-14.

" ADAMS, K. L., y BRINK, D. T. (Eds.). 1990. Perspectives on Official English: The Campaign for English as the Official Language of the USA. Nueva York: Mouton de Gruyter.

" AGHA, A. 2005. “Voice, Footing, Enregisterment”. Journal of Linguistic Anthropology, 15(1): 38-59.

》AGHA, A. 2007. Language and Social Relations. Cambridge: Cambridge University Press.

» ALIM, H. S. y SMITHERMAN, G. 2012. Articulate While Black: Barack Obama, Language and Race in the US. Nueva York: Oxford University Press.

» BALL, S., MAGUIRE, M. y BRAUN, M. 2012. How Schools Do Policy: Policy Enactments in Secondary Schools. Londres: Routledge.

" BLOMMAERT, J. 1996. "Language Planning as a Discourse on Language and Society: The Linguistic Ideology of a Scholarly Tradition". Language Problems \& Language planning, 20(3): 199-222.

" BLOMMAERT, J. 2005. Discourse. Nueva York: Cambridge University Press.

» BLOMMAERT, J. 2010. The Sociolinguistics of Globalization. Nueva York: Cambridge University Press.

» BLOMMAERT, J., COLLINS, J., HELLER, M., RAMPTON, R., SLEMBROUCK, S. y VERSCHUEREN, J. (Eds.). 2003. Ethnography, Discourse, and Hegemony. Special issue of Pragmatics 13(1).

" BLOMMAERT, J., COLLINS, J. y SLEMBROUCK, S. 2005. "Spaces of Multilingualism". Language \& Communication, 25: 197-206.

» BOURDIEU, Pierre. 1977. Outline of a Theory of Practice. Cambridge: Cambridge University Press.

»COLLINS, J. 2012. "Migration, Sociolinguistic Scale and Educational Reproduction". Anthropology \& Education Quarterly, 43(2): 192-213.

" COLLINS, J. y Blot, R. 2003. Literacy and Literacies. Nueva York: Cambridge.

"COLLINS, J. y LA SANTA, A. 2006. "Analyzing Ethnicity and Class as Communicative Practices". Working Papers in Urban Languages and Literacies, 47. Londres: Kings College. http://www.kcl.ac.uk/schools/sspp/education/research/groups/lg/wpull.html

» COLLINS, J., SLEMBROUCK, S. y BAYNHAM, M. (Eds.). 2009. Globalization and Language in Contact: Scale, Migration, and Communicative Practice. Londres: Continuum. Congress, U.S. 2007. Impact of No Child Left Behind on English Language Learners. Hearing Before the Subcommittee on Early Childhood, Elementary and Secondary Education, Committee on Education and Labor, U.S. House of Representatives. 11oth Congress, First Session. Serial No. 110-14. Printed for the use of the Committee on Education and Labor.

" CRAWFORD, J. 2001. At War With Diversity. Buffalo: Multilingual Matters.

"DE GENOVA, N. 2005. Working the Boundaries: Race, Space, and 'Illegality' in Mexican Chicago. Berkeley: University of California.

" FASSIN, D. 2011. "Policing Borders, Producing Boundaries. The Governmentality of Immigration in Dark Times". Annual Review of Anthropology, 40: 213-226. 
»FOLEY, D. 2008 [1990]. Learning Capitalist Culture: Deep in the Heart of Tejas, 2da. Ed. Filadelfia: University of Pennsylvania Press.

» FOUCAULT, M. 1991. “Governmentality”. En: G. Burchnell, C. Gordon, y P. Miller (Eds.). The Foucault Effect: Studies in Governmentality. Londres: Wheatsheaf.

» FRIEDMAN, J. 2004. “Globalization”. En: D. Nugent y J. Vincent (Eds.). A Companion to the Anthropology of Politics. Oxford: Blackwell. pp. 179-197.

» FRY, R. 2008. The Role of Schools in the English Language Learner Achievement Gap. Washington: Pew Hispanic Research Center.

" GOFFMAN, Erving. 1981. “Footing”. En: Forms of Talk. Filadelfia: University of Pennsylvania. pp. 124-159.

» GUPTA, A. y FERGUSON, J. 2002. "Spatializing States: Toward an Ethnography of Neoliberal Governmentality”. American Ethnologist, 29(4): 981-1002.

» HARVEY, D. 2005. A Brief History of Neo-liberalism. Nueva York: Oxford University Press.

» HAUGEN, E. 1966. “Dialect, Language, Nation”. American Anthropologist, 68(4), 922-935.

» HENWOOD, D. 2011. “Explaining test scores”. Left Business Observer 131, febrero, 3, 7.

» HONG, C. 2006. Learning other cultures' ways of knowing: Literacy and subjectivity among Korean students learning English. Dissertation, Department of Reading, University at Albany.

» HORNBERGER, N. y VAISH, V. 2008. “Multilingual language policy and school linguistic practice: globalization and English-language teaching in India, Singapore and South Africa". Compare, 1: 1-15.

» HUNTINGTON, S. 2004 “The Hispanic Challenge”. Foreign Policy, marzo-abril: www.foreignpolicy.com

» HYMES, D. 1996 [1975]. "Report from an Underdeveloped Country: Toward Linguistic Competence in the United States". En: Ethnography, Linguistics, Narrative Inequality: Toward an Understanding of Voice. Londres: Taylor and Francis. pp. 63-105.

» JENCKS, C. 1972. Inequality: A Reassessment of the Effect of Family and Schooling in America. Nueva York: Basic Books.

» LEE, S. 1996. Unraveling the ,Model Minority“ Stereotype: Listening to Asian American Youth. Nueva York: Teachers College Press.

» MCCARTY, T. 2010. “Introducing Ethnography and Language Policy”. En: T. McCarty (Ed.), Ethnography and Language Policy. Nueva York: Routledge. pp. 1-28.

» MCDERMOTT, R., RALEY, J. y SEYER-OCHI, I. 2009. "Race and Class in a Culture of Risk”. Review of Research in Education, marzo, 33: 101-116.

» MENKEN, K. 2008. English Learners Left Behind: Standardized Testing as Language Policy. Buffalo, NY: Multilingual Matters.

» NASAW, D. 1979. Schooled to Order: A Social History of Public Schooling in the United States. Nueva York: Oxford University Press.

» NO CHILD LEFT BEHIND Act of 2001, 2002. Public Law 107-110-January 8, 2002. 107th Congress. Retrieved March 20, 2011. http://www2.ed.gov/policy/elsec/leg/eseao2/107-110. pdf

» PARK, K. 1996. “The Use and Abuse of Race and Culture: Black-Korean Tension in America”. American Anthropologist, 89(3): 492-499. 
" PERRY, T. y DELPIT, L. 1998. The Real Ebonics Debates: Power, Language and the Education of African-American Children. Boston: Beacon Press.

》 PRATT, M. 1991. "Arts of the Contact Zone". Profession, 91: 33-40.

" RAMPTON, B., HARRIS, R., COLLINS, J, y BLOMMAERT, J. 2008. “Language, Class and Education". En: N. Hornberger y S. May (Eds.). Kluwer Encyclopedia of Language and Education. Berlín: Springer. pp. 71-81.

» RAVITCH, D. 2010. The Death and Life of the Great American School System. Nueva York: Basic Books.

"ROTHSTEIN, R. 2004. Class and Schools: Using Social, Economic, and Education Reform to Close the Black-White Achievement Gap. Nueva York: Teachers College \& Economic Policy Institute.

» SCOTT, J. 1998. Seeing Like a State: How Certain Schemes to Improve the Human Condition Have Failed. New Haven, CT: Yale University Press.

" SHANKAR, S. 2008. Desi Land: Teen Culture, Class, and Success in Silicon Valley. Durham, NC: Duke University Press.

"SILVERSTEIN, M. 2003. "The Whens and Wheres - As Well As Hows - of Ethnolinguistic Recognition". Public Culture, 15(3): 531-557.

"STEGER, M. 2003. Globalization: A Short Introduction. Nueva York: Oxford University Press.

" TROUILLOT, M.-R. 2001. "The Anthropology of the State in an Age of Globalization: Close Encounters of a Deceptive Kind". Current Anthropology, 42(1): 125-138.

" URCIUOLI, B. 1996. Exposing Prejudice: Puerto Rican Experiences of Language, Race, and class. Boulder: Westview.

"ZENTELLA, A.-C. 1997. "The Hispanophobia of the Official English movement in the US". International Journal of the Sociology of Language, 127: 71-86.

» ZENTELLA, A.-C. (Ed.). 2005. Building on Strength. Nueva York: Teachers College Press. 
